\title{
Short-duration, submaximal intensity exercise stress combined with adenosine triphosphate decreases artifacts in myocardial perfusion single-photon emission computed tomography
}

Yukinori Shinoda, Koichi Tachibana, Tomoko Minamisaka, Hidetada Fukuoka, Hirooki Inui, Keisuke Ueno, Soki Inoue, Kentaro Mine, Kumpei Ueda and Shiro Hoshida* (D)

\begin{abstract}
Background: Myocardial perfusion single-photon emission computed tomography (SPECT) imaging with stress is a useful examination for detecting coronary artery disease. Since the presence of artifacts is remaining challenges, we aimed to define the minimum intensity of low-grade exercise stress levels combined with drug stress to reduce undesired artifacts and their related factors.

Methods: We divided patients with suspicious coronary artery disease into 4 groups as follows: group A, adenosine triphosphate (ATP) for 6 min; group A $+25 \mathrm{~W}$, ATP $+25 \mathrm{~W}$ exercise for 6 min; group A $+35 \mathrm{~W}$, ATP +35 W exercise for 6 min; group A $+45 \mathrm{~W}$, ATP $+45 \mathrm{~W}$ exercise for $6 \mathrm{~min}$ ) and enrolled only those whose summed stress scores were $<3$. Undesired artifacts were evaluated on the basis of heart-to-liver activity $(H / L)$ ratio and heart-to-10 pixels below the heart $(H /$ below the $H)$ ratio.

Results: The logarithmic values of $H / L$ and $H /$ below the $H$ ratios were significantly higher in groups $A+35 \mathrm{~W}$ and $A+45 \mathrm{~W}$ than in group $\mathrm{A}(p<0.05$, each). In all the patients, the logarithmic values of $H / L$ and $H /$ below the $H$ ratios positively correlated with the increment of rate pressure product (RPP, $p=0.002$ and $p=0.005$, respectively) after stress in the univariate analysis. The left ventricular end-diastolic volume (LVEDV) after stress $(p=0.002)$ negatively correlated with the logarithmic value of $H /$ /below the $H$ ratio, but not $H / L$ ratio. Although the increment of RPP was independently associated with the logarithmic values of both $H / L(p=0.001)$ and $H /$ below the $H$ ratios $(p=0.005)$, LVEDV was also independently associated with the logarithmic value of $H /$ /below the $H$ ratio $(p<0.001)$ in multivariate regression analysis under adjusting with age and sex.
\end{abstract}

Conclusion: ATP plus $\geq 35 \mathrm{~W}$ exercise stress for 6 min was useful for reducing undesired artifacts after stress in myocardial perfusion SPECT. LVEDV after stress in addition to the increment of RPP was independently associated with the $H /$ below the $H$ ratio, but not the $H / L$ ratio.

Keywords: Adenosine triphosphate, Artifacts, End-diastolic volume, Exercise, Myocardial perfusion imaging, Rate pressure product

\footnotetext{
* Correspondence: shiro.hoshida@hosp-yao.osaka.jp

Department of Cardiovascular Medicine, Yao Municipal Hospital, 1-3-1

Ryuge-cho, Yao, Osaka 581-0069, Japan
}

(c) The Author(s). 2020 Open Access This article is licensed under a Creative Commons Attribution 4.0 International License, which permits use, sharing, adaptation, distribution and reproduction in any medium or format, as long as you give appropriate credit to the original author(s) and the source, provide a link to the Creative Commons licence, and indicate if changes were made. The images or other third party material in this article are included in the article's Creative Commons licence, unless indicated otherwise in a credit line to the material. If material is not included in the article's Creative Commons licence and your intended use is not permitted by statutory regulation or exceeds the permitted use, you will need to obtain permission directly from the copyright holder. To view a copy of this licence, visit http://creativecommons.org/licenses/by/4.0/ The Creative Commons Public Domain Dedication waiver (http://creativecommons.org/publicdomain/zero/1.0/) applies to the data made available in this article, unless otherwise stated in a credit line to the data. 


\section{Background}

It is well known that myocardial single-photon emission computed tomography.

(SPECT) imaging is useful for detecting patients with significant myocardial ischemia.

These patients can then be assessed for coronary intervention therapy. Streak artifacts are the most common source of error in myocardial SPECT imaging. Stress with vasodilators has become increasingly used in myocardial perfusion SPECT, but high liver activity adjacent to the inferior wall results from oversubtraction of the activity from the inferior wall $[1,2]$. Myocardial tracer uptake was greatest with administration of vasodilators, such as adenosine, and this effect was not attenuated by combining vasodilator administration with exercise [3]. Although adding low-level exercise stress to drug stress may help overcome some of the limitations of drug infusion alone and is useful for reducing the streak artifact [4-6], no direct comparison has been made between drug stress and the stress combined with bicycle exercise at various low grades. In this study, we hypothesized a certain grade, but not maximum grade, of bicycle exercise protocol is adequate to avoid streak artifacts when combining a 6-min infusion with the adenosine precursor, adenosine triphosphate (ATP), as compared with the standard ATP-only protocol. We evaluated the differences in the reduction of undesired artifacts between two different background regions, as well as the differences in the relevant clinical factors on myocardial perfusion SPECT in patients with suspicious coronary artery disease. We only included patients whose summed stress scores (SSSs) were $<3$ for a robust and accurate evaluation of artifacts.

\section{Methods}

Subjects with suspected angina pectoris who were unable to generate adequate stress during exercise because of antianginal medications or confounding factors that might have hindered them from achieving the target heart rate underwent elective $99 \mathrm{mTc}$-tetrofosmin stress myocardial perfusion imaging (MPI). The patients $(n=$ 280, from December 2015 to September 2017) were randomly allocated to one of the four stress protocols by an envelope method ( $n=70$ each) as follows: ATP $[7,8]$ at $120 \mu \mathrm{g} / \mathrm{kg}$ for $6 \mathrm{~min}$ (group A) and ATP at $120 \mu \mathrm{g} / \mathrm{kg}$ for 6 min concomitantly combined with various exercise intensities for $6 \mathrm{~min}$ at 25, 35, and $45 \mathrm{~W}$ (groups $\mathrm{A}+25$ $\mathrm{W}, \mathrm{A}+35 \mathrm{~W}$, and $\mathrm{A}+45 \mathrm{~W}$, respectively). The subjects exercised on a bicycle ergometer and received $110 \mathrm{MBq}$ of ${ }^{99 \mathrm{~m}} \mathrm{Tc}$ tetrofosmin injection at $3 \mathrm{~min}$ after initiation of ATP infusion. Image acquisition was initiated $45 \mathrm{~min}$ after the ${ }^{99 \mathrm{~m}} \mathrm{Tc}$ injection. A 2-min planar image was obtained, followed immediately by the acquisition of a standard gated SPECT image. Perfusion imaging was performed using a 2-detector gamma camera (ADAC
Forte), with a circular $180^{\circ}$ orbit. The perfusion data were displayed in a 17-segment model in accordance with the American Society of Nuclear Cardiology guidelines [9]. The 17 segments for each image were scored from 0 to 4 , with 0 indicating no perfusion defect and 4 indicating no tracer. In this study, we enrolled only patients whose SSSs were $<3$ because of robust clarification of artifacts. Therefore, we analyzed only the data of 109 patients (group $\mathrm{A}, n=23$; group $\mathrm{A}+25 \mathrm{~W}, n=34$; group $\mathrm{A}+35$ $\mathrm{W}, n=28$; and group $\mathrm{A}+45 \mathrm{~W}, n=24)$. Whereas the stress and rest studies were interpreted together in the usual manner, the four-group images were analyzed in random order to avoid bias by the expert reader. The exclusion criteria were as follows: a contraindication to adenosine (moderate to severe chronic obstructive pulmonary disease or asthma, second- or third-degree atrioventricular block or sinus node disease, known as hypersensitivity to adenosine); hemodynamic instability; decompensated congestive heart failure; or the use of theophylline or dipyridamole within the preceding $48 \mathrm{~h}$. Patient characteristics were examined in terms of laboratory data, medications, and comorbidities. Systolic and diastolic blood pressure and heart rate were recorded before and immediately after exercise or 6 min after ATP infusion. This study complied with the tenets of the Declaration of Helsinki, and all patients provided written informed consent to participate.

Undesired background artifacts were evaluated using two different modes. To obtain the heart-to-liver activity $(H / L)$ ratio, the regions of interest were drawn around the heart and liver, excluding the gall bladder. "Heart counts" and "liver counts" were obtained from the point of maximum counts in each region of interest. Undesired artifacts were also evaluated on the basis of heart-to-10 pixels below the heart ratio $(H /$ below the $H$ ratio). The profile lines were placed on the heart and below the heart from the bottom of the heart image to 10 pixels. "Heart counts" were obtained from the maximum count in the profile line, and "below heart counts" were obtained from the minimum count in the profile line. These ratios were determined from the anterior planar images. The image readers were blinded to patient characteristics and group assignment.

Continuous variables are expressed as means \pm standard deviations, whereas categorical variables are presented as percentages. Differences in categorical variables among the groups were assessed using chisquare tests $(4 \times 2)$, while those in continuous variables were assessed using one-way analysis of variance, and those between two groups were made using a post hoc Bonferroni test. The significance of the correlation between two variables was assessed with regression analysis. A $p$ value of $<0.05$ was considered statistically significant. 


\section{Results}

The clinical characteristics of the patients are shown in Table 1 . No significant differences in age, sex, incidence of comorbidities, medications, and laboratory data except for low-density lipoprotein cholesterol levels were found among the four groups. The values of the hemodynamic parameters were significantly higher in the groups with concomitant exercise than in those without exercise (Table 2). Left ventricular end-diastolic volume (LVEDV), end-systolic volume, and ejection fraction were not significantly different among the four groups before and after the protocol.
In terms of SPECT data, maximum signals from the heart were slightly decreased after each exercise protocol. In contrast, maximum signals from the liver and minimum signals below the heart were significantly reduced in association with exercise (ANOVA, $p=0.010$ and $p=0.045$, respectively). The logarithmic value of the heart-to-background count ratios such as the $H / L$ ratio and $H$ /below the $H$ ratio was significantly higher in groups $\mathrm{A}+35 \mathrm{~W}$ and $\mathrm{A}+45 \mathrm{~W}$ than in group A (Fig. 1).

In all the patients, the logarithmic values of $H / L$ and $H$ /below the $H$ ratios positively correlated with heart rate $(p=0.004$ and $p=0.008$, respectively), rate pressure product (RPP; $p=0.005$ and $\mathrm{p}=0.008$, respectively), and

Table 1 Patient characteristics

\begin{tabular}{|c|c|c|c|c|c|c|}
\hline & Total & Group & & & & $p$ \\
\hline & & A & $A+25 W$ & $A+35 W$ & $A+45 W$ & \\
\hline & $n=109$ & $n=23$ & $n=34$ & $n=28$ & $n=24$ & \\
\hline Age, years & $70 \pm 10$ & $75 \pm 9$ & $68 \pm 10$ & $69 \pm 10$ & $71 \pm 8$ & 0.056 \\
\hline Male, \% & 41 & 48 & 32 & 39 & 50 & 0.508 \\
\hline Previous MI, \% & 4 & 13 & 3 & 0 & 0 & 0.051 \\
\hline Previous PCI, \% & 16 & 39 & 12 & 11 & 4 & 0.051 \\
\hline Cerebrovascular disease, $\%$ & 17 & 31 & 7 & 14 & 25 & 0.071 \\
\hline Peripheral artery disease, \% & 8 & 22 & 3 & 7 & 4 & 0.061 \\
\hline Hypertension, \% & 62 & 73 & 65 & 54 & 58 & 0.479 \\
\hline Dyslipidemia, \% & 57 & 68 & 62 & 46 & 54 & 0.051 \\
\hline Diabetes mellitus, \% & 41 & 46 & 38 & 46 & 33 & 0.782 \\
\hline Atrial fibrillation, \% & 5 & 9 & 3 & 7 & 0 & 0.445 \\
\hline Current Smoking, \% & 15 & 23 & 15 & 11 & 13 & 0.715 \\
\hline Laboratory data & & & & & & \\
\hline $\mathrm{Hb}, \mathrm{g} / \mathrm{dL}$ & $13.6 \pm 1.7$ & $12.7 \pm 1.7$ & $13.6 \pm 1.4$ & $14.1 \pm 1.9$ & $13.9 \pm 1.8$ & 0.051 \\
\hline $\mathrm{HbA} 1 \mathrm{c}, \%$ & $7.8 \pm 2.6$ & $6.7 \pm 1.2$ & $8.2 \pm 2.7$ & $8.4 \pm 3.2$ & $7.4 \pm 2.5$ & 0.216 \\
\hline $\mathrm{UA}, \mathrm{mg} / \mathrm{dL}$ & $5.4 \pm 1.5$ & $5.1 \pm 0.8$ & $5.2 \pm 1.5$ & $5.8 \pm 1.8$ & $5.6 \pm 1.8$ & 0.415 \\
\hline $\mathrm{LDL}-\mathrm{C}, \mathrm{mg} / \mathrm{dL}$ & $122 \pm 35$ & $108 \pm 29$ & $122 \pm 30$ & $139 \pm 35$ & $113 \pm 41$ & 0.036 \\
\hline $\mathrm{HDL}-\mathrm{C}, \mathrm{mg} / \mathrm{dL}$ & $54 \pm 26$ & $53 \pm 15$ & $61 \pm 41$ & $51 \pm 10$ & $48 \pm 20$ & 0.493 \\
\hline Creatinine, $\mathrm{mg} / \mathrm{dL}$ & $0.92 \pm 0.64$ & $1.23 \pm 1.15$ & $0.77 \pm 0.21$ & $0.81 \pm 0.37$ & $0.97 \pm 0.45$ & 0.054 \\
\hline $\mathrm{BNP}, \mathrm{pg} / \mathrm{mL}$ & $49(22,78)$ & $58(22,208)$ & $48(23,68)$ & $59(15,65)$ & $40(11,63)$ & 0.067 \\
\hline Medications & & & & & & \\
\hline ADA, \% & 22 & 14 & 27 & 29 & 17 & 0.167 \\
\hline ATA, $\%$ & 22 & 36 & 27 & 11 & 17 & 0.192 \\
\hline$\beta$ blocker, \% & 14 & 14 & 18 & 18 & 4 & 0.440 \\
\hline $\mathrm{CCB}, \%$ & 46 & 55 & 47 & 46 & 38 & 0.634 \\
\hline Diuretics, \% & 8 & 14 & 6 & 11 & 4 & 0.374 \\
\hline Nitrates, \% & 7 & 14 & 9 & 7 & 0 & 0.636 \\
\hline RAS-I, \% & 37 & 36 & 27 & 36 & 54 & 0.075 \\
\hline Statin, \% & 41 & 57 & 44 & 21 & 42 & 0.462 \\
\hline
\end{tabular}

Data are mean \pm SD or percentage except for BNP level (median, 25-75\%)

$M I$ myocardial infarction, $P C l$ percutaneous coronary intervention, $H b$ hemoglobin, UA uric acid, $L D L-C$ low-density lipoprotein cholesterol; $H D L-C$ high-density lipoprotein cholesterol, $B N P$ brain natriuretic peptide, $A D A$ antidiabetic agents, $A T A$ antithrombotic agents, CCB calcium-channel blocker, RAS-I renin-angiotensin system inhibitor 
Table 2 Hemodynamic and SPECT data

\begin{tabular}{|c|c|c|c|c|c|c|}
\hline & \multirow[t]{2}{*}{ Total } & \multicolumn{4}{|l|}{ Group } & \multirow{2}{*}{$\begin{array}{l}p \\
\text { Value }\end{array}$} \\
\hline & & $A$ & $A+25 W$ & $A+35 W$ & $A+45 W$ & \\
\hline \multicolumn{7}{|c|}{ Hemodynamic parameters } \\
\hline SBP pre, $\mathrm{mmHg}$ & $144 \pm 20$ & $144 \pm 21$ & $148 \pm 18$ & $137 \pm 22$ & $148 \pm 21$ & 0.182 \\
\hline post, $\mathrm{mmHg}$ & $178 \pm 41$ & $146 \pm 26$ & $187 \pm 39$ & $175 \pm 40$ & $202 \pm 37$ & $<0.001$ \\
\hline DBP pre, $\mathrm{mmHg}$ & $76 \pm 15$ & $74 \pm 15$ & $77 \pm 13$ & $74 \pm 16$ & $80 \pm 16$ & 0.387 \\
\hline post, $\mathrm{mmHg}$ & $80 \pm 28$ & $69 \pm 19$ & $77 \pm 18$ & $80 \pm 38$ & $95 \pm 30$ & 0.013 \\
\hline HR pre, bpm & $76 \pm 13$ & $76 \pm 12$ & $75 \pm 12$ & $76 \pm 17$ & $78 \pm 10$ & 0.905 \\
\hline post, bpm & $105 \pm 22$ & $80 \pm 12$ & $107 \pm 18$ & $105 \pm 17$ & $124 \pm 17$ & $<0.001$ \\
\hline RPP pre & $10,902 \pm 2282$ & $10,854 \pm 2236$ & $11,054 \pm 2296$ & $10,266 \pm 2260$ & $11,476 \pm 2241$ & 0.28 \\
\hline post & $19,109 \pm 6880$ & $11,690 \pm 2916$ & $20,089 \pm 5625$ & $18,377 \pm 4741$ & $25,685 \pm 6467$ & $<0.001$ \\
\hline delta & $8207 \pm 6250$ & $836 \pm 2265$ & $9035 \pm 4769$ & $8111 \pm 3554$ & $14,209 \pm 6173$ & $<0.001$ \\
\hline \multicolumn{7}{|l|}{ SPECT data } \\
\hline EDV stress, mL & $67 \pm 23$ & $64 \pm 24$ & $72 \pm 26$ & $66 \pm 23$ & $65 \pm 16$ & 0.505 \\
\hline rest, $\mathrm{mL}$ & $68 \pm 23$ & $65 \pm 24$ & $71 \pm 26$ & $68 \pm 23$ & $66 \pm 18$ & 0.721 \\
\hline ESV stress, mL & $21 \pm 13$ & $21 \pm 12$ & $24 \pm 16$ & $21 \pm 11$ & $18 \pm 9$ & 0.46 \\
\hline rest, $\mathrm{mL}$ & $20 \pm 13$ & $20 \pm 12$ & $20 \pm 13$ & $20 \pm 11$ & $17 \pm 9$ & 0.672 \\
\hline EF stress, \% & $70 \pm 10$ & $68 \pm 11$ & $70 \pm 12$ & $69 \pm 8$ & $73 \pm 7$ & 0.286 \\
\hline rest, \% & $73 \pm 9$ & $71 \pm 9$ & $73 \pm 9$ & $72 \pm 9$ & $76 \pm 8$ & 0.286 \\
\hline SSS & $1.3 \pm 1.2$ & $1.0 \pm 1.2$ & $1.2 \pm 1.1$ & $1.6 \pm 1.1$ & $1.4 \pm 1.2$ & 0.345 \\
\hline SRS & $1.3 \pm 1.6$ & $1.0 \pm 21.9$ & $1.1 \pm 1.3$ & $2 \pm 1.7$ & $1.1 \pm 1.2$ & 0.06 \\
\hline SDS & $0.7 \pm 0.9$ & $0.7 \pm 1.1$ & $0.7 \pm 0.8$ & $0.6 \pm 0.6$ & $0.9 \pm 1.1$ & 0.685 \\
\hline
\end{tabular}

Data are mean \pm SD

$S B P$ systolic blood pressure, $D B P$ diastolic blood pressure, $H R$ heart rate, $R P P$ rate pressure product, EDV end-diastolic volume, ESV end-systolic volume, EF ejection fraction, SSS summed stress score, SRS summed rest score, SDS summed difference score

the increment of RPP (delta RPP; $p=0.002$ and $\mathrm{p}=$ 0.005 , respectively) after stress in the univariate analysis (Table 3). The LVEDV after stress $(\mathrm{p}=0.002)$ negatively correlated with the logarithmic value of $H$ /below the $H$ ratio, but not $H / L$ ratio. Although male sex was independently associated with the logarithmic values of both $H / L$ ratio $(p=0.020)$ and $H /$ below the $H$ ratio $(p=$ 0.001 ) in the multivariate regression analysis, LVEDV was also independently associated with the logarithmic value of $H$ /below the $H$ ratio $(p<0.001$; Table 3$)$.

No significant side effects except for mild nausea and hypotension attributable to the ATP infusion in combination with exercise were observed, and our protocol was well tolerated in this study.

\section{Discussion}

The main finding of our study was that concomitant 6min low-grade exercise supplementation with $\geq 35 \mathrm{~W}$, through the use of the bicycle protocol, increased heartto-background count ratios such as $H / L$ and $H /$ below the $H$ ratios in the patients who underwent ATP stress MPI. The other findings of this study were that in the case of the $H$ /below the $H$ ratio, the artifact was independently associated with the LVEDV after exercise in addition to the increment of RPP.

Exercise stress is well known to increase heart-tobackground count ratios as compared with drug stress alone and to reduce hepatic tracer uptake relative to the heart. Side effects are common during standard adenosine stress testing. However, few significant side effects attributable to the ATP infusion in combination with exercise were observed, and this procedure was well tolerated in this study. It is conceivable that exercise increases sympathetic nerve activity, which improves atrioventricular conduction. Therefore, noncardiac side effects such as hypotension, and major arrhythmias such as atrioventricular block are significantly reduced after exercise stress [10]. Exercise also suppresses the vasodilation of adenosine in diaphragmatic regions and the heart-to-background count ratio is higher in the exercise groups in correlation with the exercise level achieved [3]. Samady et al. found that a 6-min adenosine infusion with concomitant low-level treadmill exercise reduced unfavorable side effects, enhanced image quality, and may have resulted in greater detection of ischemia [11]. Enhancement of image quality was also observed when the adenosine infusion study was performed as 


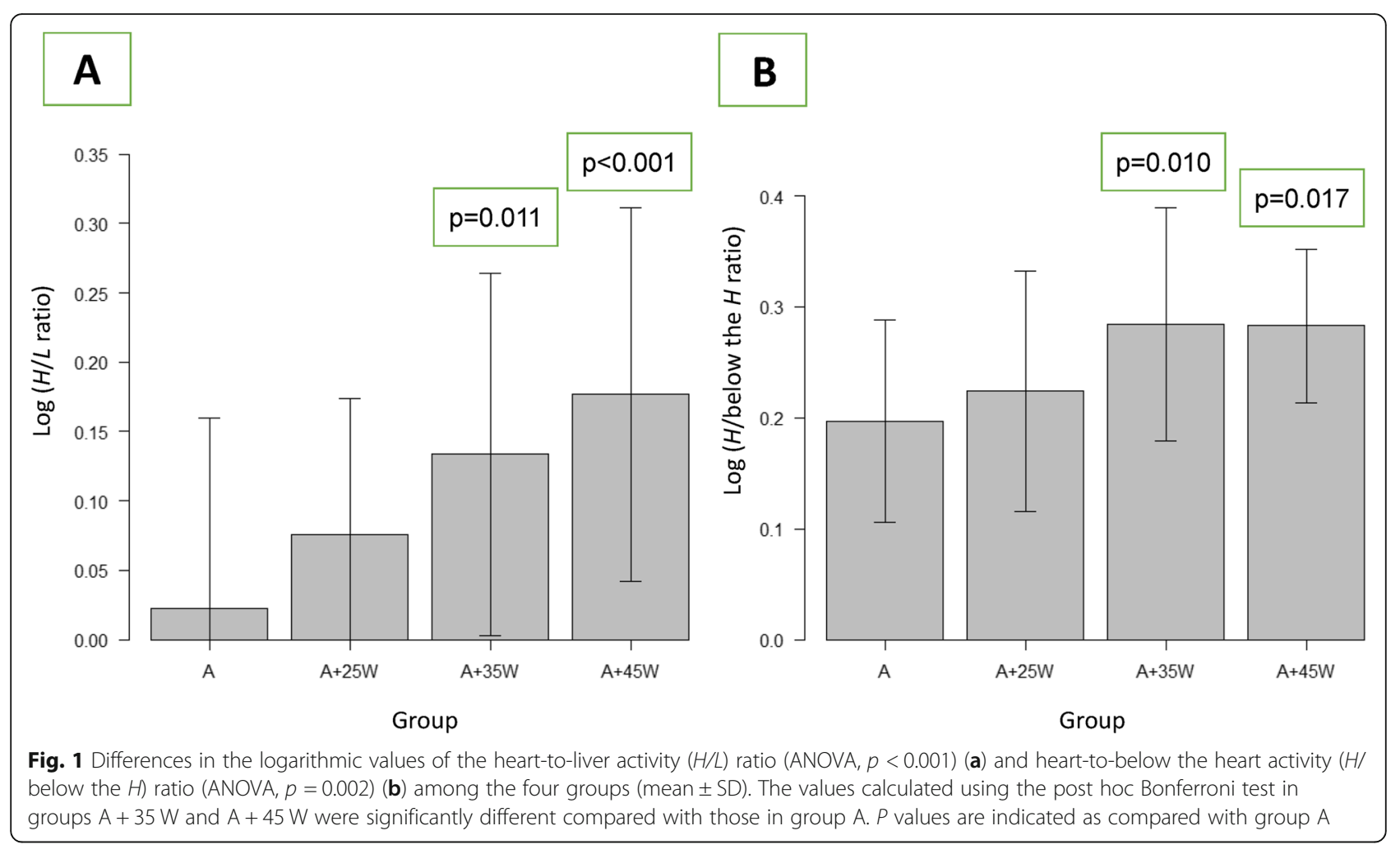

compared with the bicycle-exercise protocol in patients treated with beta-blockade [12]. However, the opposite results were reported by Jamil et al., who showed no change in defect size or severity following exercise, compared with the standard 6-min adenosine infusion [13].

A clear increase in $H / L$ ratio is an important finding because an increased $H / L$ ratio has been shown to result in fewer artifacts in the inferior and inferoseptal regions of the heart $[1,2]$. In our study, we included only patients whose SSSs were $<3$ to evaluate precisely the extent of background level. When combined with ATP plus short-duration exercise stress, mild stress was adequate to obtain a significant quality image. Some differences were found between the results in the two regions regarding the quantification of the target-tobackground ratio. The $H /$ below the $H$ ratio represents a comparison of the image quality of the heart with those of organs adjacent to the heart, such as the diaphragm, intestine, and other digestive tissues, and was inversely dependent on LVEDV in association with the increment of RPP. Enlargement of the left ventricle may reduce the sharpness of the SPECT image because of the increase in the dispersion of ${ }^{99 \mathrm{~m}} \mathrm{Tc}$ tetrofosmin in case of $H /$ below the $H$ ratio. By contrast, male sex, irrespective of

Table 3 Correlation with heart-to-background activity ratio

\begin{tabular}{|c|c|c|c|c|}
\hline & \multicolumn{2}{|c|}{ Univariate } & \multicolumn{2}{|c|}{ Multivariate } \\
\hline & $r$ Value & $p$ Value & $p$ Value & Coefficient $(95 \% \mathrm{Cl})$ \\
\hline \multicolumn{5}{|c|}{$\log (H / L$ ratio $)$} \\
\hline Age & 0.030 & 0.752 & 0.603 & $0.0006(-0.0018 \sim 0.0032)$ \\
\hline Male & 0.196 & 0.040 & 0.020 & $0.0591(0.0093 \sim 0.1089)$ \\
\hline delta RPP & 0.283 & 0.002 & 0.001 & $0.0001(0.0001 \sim 0.0001)$ \\
\hline \multicolumn{5}{|c|}{$\log (H /$ below the $H$ ratio) } \\
\hline Age & 0.027 & 0.773 & 0.686 & $-0.0003(-0.0023 \sim 0.0015)$ \\
\hline Male & 0.126 & 0.188 & 0.001 & $0.0677(0.0275 \sim 0.1079)$ \\
\hline delta RPP & 0.263 & 0.005 & 0.005 & $0.0001(0.0001 \sim 0.0001)$ \\
\hline EDVex & 0.289 & 0.002 & $<0.001$ & $-0.0019(-0.0028 \sim-0.0010)$ \\
\hline
\end{tabular}

$\overline{C l}$ Confidence interval, $H / L$ heart-to-liver activity ratio, $H /$ below the $H$ heart-to-below the heart, $R P P$ rate pressure product, EDVex end-diastolic volume after exercise 
left ventricular size, was an independent factor for $H / L$ or $H /$ below the $H$ ratio. Sex-related differences in artifacts may result from the grade of fat tissue and complicated body structures, including the lung, spine, and chest wall. A pertinent question that should be answered in the future is how a higher image quality can be obtained in patients with enlarged left ventricles when the use of a new type of stress method is becoming widespread in myocardial perfusion SPECT.

A considerable interpatient variability exists in the heart-to-background count ratios, but some extent of the exercise level achieved greater heart-to-background count ratio, which may depend on the extent of the RPP. A short-duration exercise stress of $\geq 35 \mathrm{~W}$ may enhance sympathetic activity abruptly and adequately, thus leading to the desirable results. Improvement of the heart-to-background count ratio was present at the lower exercise levels, which most patients could be expected to achieve. Six-min ATP infusion with a moderately low-grade exercise protocol during the same period is preferable because it can be incorporated into the standard drug stress regimen with no time loss.

\section{Limitations}

Depending on the protocol design, the type of tracer, moment of tracer injection, and type and duration of exercise may vary [14-18] and elicit different results. Whether these issues have any effects on the accuracy of the perfusion study are currently unclear. We could not use SPEC $\mathrm{T}$-computed tomography scanner to reduce artifacts. As we randomly assigned patients into four groups but enrolled only those with SSSs of $<3$, the number of patients differed among the groups. Under this condition, the defect severity and sensitivity to coronary artery disease in each group could not be evaluated.

\section{Conclusion}

ATP administration concomitant with mild exercise stress of $\geq 35 \mathrm{~W}$ was useful for reducing undesired artifacts evaluated on the basis of heart-to-background ratio. $H$ /below the $H$ ratio, but not $H / L$ ratio, was associated with the LVEDV after stress in addition to male sex and the increment of RPP. The factors that cause artifacts might be different between target organs.

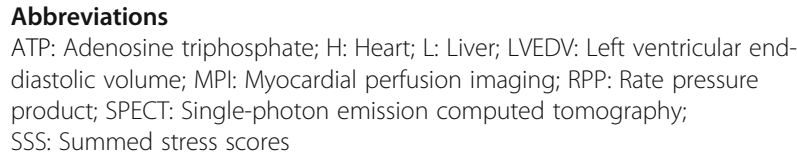

ATP: Adenosine triphosphate; H: Heart; L: Liver; LVEDV: Left ventricular enddiastolic volume; MPI: Myocardial perfusion imaging; RPP: Rate pressure product; SPECT: Single-photon emission computed tomography; SSS: Summed stress scores

\section{Acknowledgements}

None.

\section{Availability of data and material}

The raw data may be made available upon reasonable request from the corresponding authors.

\section{Authors' contributions}

(1) conception and design of the study, or acquisition of, or analysis and interpretation of data: YS, TM, HF, HI, KU, SI, KM, KU, (2) drafting the article or revising it critically for important intellectual content: YS, KT, SH and (3) final approval of the version to be submitted: all authors have read and approved the submission of the manuscript.

\section{Funding}

None.

\section{Ethics approval and consent to participate}

This study complied with the tenets of the Declaration of Helsinki, and the protocol was approved by the ethics committee of our hospital (Ethics Committee of Yao Municipal Hospital). All patients provided written informed consent to participate.

\section{Consent for publication}

Not Applicable.

\section{Competing interests}

The authors have no financial or other relations that could lead to a conflict of interest.

Received: 8 June 2020 Accepted: 30 September 2020

Published online: 07 October 2020

\section{References}

1. Germano G, Chua T, Kiat H, Areeda JS, Berman DS. A quantitative phantom analysis of artifacts due to hepatic activity in technetium-99m myocardial perfusion SPECT studies. J Nucl Med. 1994;35:356-9.

2. Nuyts J, Dupont P, Van den Maegdenberg V, Vluegels S, Suetens P, Mortelmans L. A study of the liver-heart artifact in emission tomography. J Nucl Med. 1995;36:133-9.

3. Pennell DJ, Mavrogeni SI, Forbat SM, Karwatowski SP, Underwood SR. Adenosine combined with dynamic exercise for myocardial perfusion imaging. J Am Coll Cardiol. 1995;25:1300-9.

4. Verzijlbergen FJ, Vermeersch PH, Laarman GJ, Ascoop CA. Inadequate exercise leads to suboptimal imaging after dipyridamole combined with low-level exercise unmasks ischemia in symptomatic patients with nondiagnostic thallium-201 scans who exercise submaximally. J Nucl Med. 1991; 32:2071-8.

5. Vitola JV, Brambatti JC, Caligaris F, Lesse CR, Noqueira PR, Joaquim Al, Loyo M, Salis FV, Paiva EV, Chalela WA, Meneghetti JC. Exercise supplementation to dipyridamole prevents hypotension, improves electrocardiogram sensitivity, and increases heart-to-liver activity ratio on Tc-99m sestamibi imaging. J Nucl Cardiol. 2001;8:652-9.

6. Holly TA, Satran A, Bromet DS, Mieres JH, Frey MJ, Elliot MD, Heller GV, Hendel RC. The impact of adjunctive adenosine infusion during exercise myocardial perfusion imaging: results of the both exercise and adenosine stress test (BEAST) trial. J Nucl Cardiol. 2003;10:291-6.

7. Ohba T, Takano H, Kunimi T, Fujita N, Kodani E, Mizuno K. Direct comparison between pharmacological stress with adenosine triphosphate disodium and exercise stress myocardial perfusion imagings. J Cardiol. 2008; 52:30-8.

8. Yao Z, Zhu H, Li W, Chen C, Wang H, Shi L, Zhang W. Adenosine triphosphate stress myocardial perfusion imaging for risk stratification of patients aged 70 years and older with suspected coronary artery disease. J Nucl Cardiol. 2017;24:429-33.

9. Cerqueira MD, Varani MS, Schwaiger M, Heo J, Iskandrian AS. Safety profile of adenosine stress perfusion imaging: results from the Adenoscan multicenter trial registry. J Am Coll Cardiol. 1994;23:384-9.

10. Elliot MD, Holly TA, Leonard SM, Hendel RC. Impact of an abbreviated adenosine protocol incorporating adjunctive treadmill exercise on adverse effects and image quality in patients undergoing stress myocardial perfusion imaging. J Nucl Cardiol. 2000;7:584-9.

11. Samady H, Wackers FJT, Joska TM, Zaret BL, Jain D. Pharmacologic stress perfusion imaging with adenosine: role of simultaneous low-level treadmill exercise. J Nucl Cardiol. 2002;9:188-96.

12. Muller-Suur R, Eriksson SV, Standberg LE, Mesko I. Comparison of adenosine and exercise stress test for quantitative perfusion imaging in patients on beta blocker therapy. Cardiology. 2001;95:112-8. 
13. Jamil G, Ahlberg AW, Elliot MD, Hendel RC, Holly T, McGill CC, Sarkis M, White MP, Mather JF, Waters DD, Heller GV. Impact of limited treadmill exercise on adenosine Tc-99m sestamibi single-photon emission computed tomographic myocardial perfusion imaging in coronary artery disease. Am J Cardiol. 1999;84:400-3.

14. Casale PN, Guiney TE, Strauss W, Boucher CA. Simultaneous low level treadmill exercise and intravenous dipyridamole stress thallium imaging. Am J Cardiol. 1988;62:799-802.

15. Laarman GJ, Bruschke AVG, Verzijlbergen FJ, Bal FT, Van der Waal EE, Ascoop CAPL. Efficacy of intravenous dipyridamole with exercise in thallium-201 myocardial perfusion scintigraphy. Eur Heart J. 1988;9:1206-14.

16. Stein I, Burt R, Oppenheim B, Schauwecker D, Fineberg N. Symptom-limited arm exercise increases detection of ischemia during dipyridamole tomographic thallium stress testing in patients with coronary artery disease. Am J Cardiol. 1995;75:568-72.

17. Sharir T, Rabinowitz B, Livschitz S, Moalcm I, Baron J, Kaplinsky E, Chouraqui P. Underestimation of extent and severity of coronary artery disease by dipyridamole stress thallium-201 single photon emission computed tomographic myocardial perfusion imaging in patients taking antianginal drugs. J Am Coll Cardiol. 1998:31:1540-6.

18. Levine MG, Ahlberg AW, Mann A, White MP, McGill CC, Mendes de Leon C, Piriz JM, WatersD HGV. Comparison of exercise, dipyridamole, adenosine, and dobutamine stress with the use of Tc-99m tetrofosmin tomographic imaging. J Nucl Cardiol. 1999;6:389-96.

\section{Publisher's Note}

Springer Nature remains neutral with regard to jurisdictional claims in published maps and institutional affiliations.

Ready to submit your research? Choose BMC and benefit from:

- fast, convenient online submission

- thorough peer review by experienced researchers in your field

- rapid publication on acceptance

- support for research data, including large and complex data types

- gold Open Access which fosters wider collaboration and increased citations

- maximum visibility for your research: over $100 \mathrm{M}$ website views per year

At $\mathrm{BMC}$, research is always in progress.

Learn more biomedcentral.com/submissions 